\title{
Introduction to A Research Agenda for Workplace Stress and Wellbeing
}

\section{E. Kevin Kelloway and Cary L. Cooper}

If the events of the past year (2020) have taught us anything, it is that planning for the future is an audacious act. The global pandemic and associated events (e.g., lockdowns and the move to remote work) have both stalled and enhanced research progress. On the one hand, disruptions in the workplace have led to well-developed research plans being stalled or rapidly reformulated to recognize the changing situation. On the other hand, the crisis has led to a renewed recognition of the importance of mental health issues and wellbeing in the workplace. Many are already predicting an "echo pandemic" (Dozois, 2020) of mental health problems arising from the Covid-19 pandemic and this will be part of the new reality faced by organizations and their employees.

Prior to the pandemic, the authors represented in this volume were approached with a request that, in itself, required some audacity. We asked individuals with established expertise in workplace wellbeing to consider their respective literatures, review what was known about their topic and to articulate an agenda for future researchers. Although the pandemic has created its own research needs (see, for example, Chapter 12), there is much more to be done to understand and positively influence workplace wellbeing. We are pleased that so many experts accepted our invitation and contributed their expertise to this volume.

\section{Why work and wellbeing?}

There is a clear need to focus on issues related to employee wellbeing. A frequently cited estimate is that one in four people (translating into more than 450 million people) will experience a significant mental health problem (National Alliance on Mental Illness [NAMI], 2019; World Health 
Organization [WHO], 2002, 2004) and mental health issues are one of the leading causes of workplace disability (Mental Health Commission of Canada [MHCC], 2012; WHO, 2019). The cost of mental health problems has been estimated to be over 135 Euros each year (5 percent of GDP) in the European Union (McDaid, 2011), between $\$ 150$ and $\$ 300$ billion annually in the United States (American Institute of Stress, 2005) and $\$ 50$ billion each year in Canada (MHCC, 2012).

Jones-Chick and Kelloway (in press) point to the inadequacy of "minimalist" attempts to address this issue. They argue that many organizations have been content to establish an Employee Assistance Program and trust that such a program will "fix" mental health issues. However, the available data suggest that such programs are typically underutilized (Attridge et al., 2013; Canadian Medical Association, 2013; Linnan et al., 2008; Reynolds \& Lehman, 2003) and that individuals experiencing mental health issues frequently go undiagnosed (Corrigan, 2004). Indeed, the individuals who are most likely to benefit from such programs may be the least likely to use them (Dimoff \& Kelloway, 2016; Hunt \& Eisenberg, 2010; Linnan et al., 2008).

Kelloway (2017) has suggested that there are clear signs that organizations are changing their orientation and moving beyond a minimalist approach to mental health issues in the workplace. In conjunction with increased societal awareness of mental health issues, organizations have become involved in actively promoting employee wellbeing. Kelloway (2017, see also Jones-Chick \& Kelloway, in press) has suggested that more comprehensive approaches to workplace mental health rest on the "three pillars" of prevention, intervention, and accommodation. That is, organizations are increasingly looking at means of reducing workplace stress and enhancing workplace conditions for employees (i.e., prevention), recognizing that organizations can, and should, assist individuals in crisis (i.e., intervention, see Dimoff \& Kelloway, 2019), and helping individuals stay at work or return to work after a period of leave (i.e. accommodation, see Kelloway, 2017).

\section{Definitional issues}

In many cases, an organizational focus on mental health is part of the evolution of the healthy workplace movement. Healthy workplace programs are "employer sponsored initiatives directed at improving the health and wellbeing of employees" (Goetzel et al., 2008, p.4). Originally focused on physical health issues (Baicker et al., 2010), such programs have typically evolved to 
include issues of psychological wellbeing as well (Kelloway, 2017). Although there is evidence supporting the effectiveness of healthy workplace programs (see, for example, Goetzel \& Ozminkowski, 2008), there are also significant concerns with research in this area which limits the conclusions that can be drawn (for a review see Dimoff et al., 2014).

Although organizations have begun to focus more on employee wellbeing, a concern for psychological factors in the workplace is by no means new. Kornhauser's (1965) seminal work identified the mental health concerns inherent in factory work and the Work in America (Secretary of Health, Education and Welfare, 1974) report drew attention to the prevalence and effects of workplace stress. In 1990, the National Institute for Occupational Safety and Health (NIOSH) identified workplace stress as one of the 10 leading causes of workplace death and declared stress to be a national epidemic (Sauter et al., 1990). The NIOSH report focused specifically on six common workplace stressors (i.e., role stress, workload and pace, work scheduling, job content and control, work-family conflict and interpersonal stressors) and a substantial body of research supports their conclusions (for a review see Kelloway \& Day, 2005).

Although the initial focus of research and practice was on the identification and reduction of workplace stressors, subsequent approaches have emphasized the provision of resources that both contribute directly to wellbeing and mitigate the effects of organizational stressors. Five such resources - recognition, opportunities for growth and development, involvement, health and safety and work-family balance - provide the basis for the psychologically healthy workplace model promoted by the American Psychological Association (APA; Grawitch, Gottschalk \& Munz, 2006). Consistent with this approach, recognition is associated with enhanced employee wellbeing (Gilbert \& Kelloway, 2018). Moreover, Gulseren et al. (in press) drew on the APA model to formulate the R.I.G.H.T. model of leadership (i.e., recognition, involvement, growth, health and safety, teamwork). When leaders provide these opportunities, employees experience enhanced wellbeing (Gulseren et al., in press).

The enactment of a national standard for psychological health and safety (Canadian Standards Association, 2013) has largely shaped the discussion about workplace wellbeing in Canada. A psychologically healthy and safe workplace is defined in the standard as a "workplace that promotes workers' psychological wellbeing and actively works to prevent harm to worker psychological health, including in negligent, reckless, or intentional ways". There are two distinct aspects of this definition - the promotion of workers' psychological wellbeing and the prevention of harm to psychological health. The defini- 
tion is consistent with the World Health Organization's definition of health as comprising "a state of complete physical, mental and social wellbeing and not merely the absence of disease or infirmity" (World Health Organization, 1948).

Similarly, common usage of the term mental health or wellbeing invokes two quite different themes. On the one hand mental health - or more accurately mental illness - refers to a set of conditions defined by diagnostic criteria as expressed in the DSM. Conditions such as clinical depression, Post-Traumatic Stress Disorder, or anxiety disorder are representative of this set of diagnosable conditions. On the other hand, the term "mental health" is also used to refer to a more positive state that goes beyond the absence of mental illness (e.g., the standard refers to the promotion of wellbeing). Ryff (1989) has offered the most well-supported model of positive functioning as comprising self-acceptance, positive relationships with others, autonomy, environmental mastery, purpose in life, and personal growth. Thus, individuals have psychological wellbeing or optimal mental health when they "like most parts of themselves, have warm and trusting relationships, see themselves developing into better people have a direction in life, are able to shape their environments and have a degree of self-determination" (Keyes, 2002, pp. 208-209).

These two aspects of mental health - mental illness and positive psychological wellbeing - do not seem to be opposite ends of a single continuum. They appear to be two moderately negatively correlated but separate dimensions of health. Moreover, these two dimensions are paralleled by discussions of physical health in which we might distinguish between being physically ill (e.g., having a flu) and being physically fit (e.g., having aerobic capacity, good cardiovascular health etc.). Thus, in discussing workplace wellbeing we are really addressing two related issues: the extent to which the organization is taking steps to reduce harm (e.g., by reducing, eliminating or mitigating the effects of workplace stressors); and the extent to which the organization is promoting the positive psychological wellbeing of employees.

\section{Methodological issues}

Even a brief perusal of the literature on work and wellbeing would evidence some common concerns with regard to research methodologies. Perhaps the most common concern is the reliance on cross-sectional self-report data that has dominated, and continues to be prevalent in, research on work and wellbeing. There is no doubt that cross-sectional research designs have a role to play 
in research (e.g., Taris et al., in press). However, there is also a clear need to move beyond such designs.

Spector and Pindek (2016) conducted a content analysis of articles published in the Journal of Occupational Health Psychology and Work \& Stress between 2010 and 2014. As a result of their review, they made five specific recommendations for research methodology. First, they suggested there was a need for inductive or exploratory methods as used in fields such as the natural sciences, in contrast to the predominant model of theory-based deduction used in occupational health psychology. This suggestion is also reflected in Quick's (see Chapter 2) call for more inter-disciplinary approaches to the study of wellbeing. Second, Spector and Pindek (2016) point to the need to understand processes and the temporal sequence of events that lead to health-related outcomes. The emergence of diary studies, or studies based on ecological momentary assessment, are a response to this call - although Taris et al. (in press) note that the analyses of these data often do not account for temporal relations and, as a result, a promising methodology often produces data that does not go beyond understanding cross-sectional relationships. Spector and Pindek (2016) also note the potential for three specific research approaches - qualitative research, longitudinal research, and research incorporating multi-level perspectives - for advancing our understanding of workplace wellbeing.

Kelloway $(2017,2020)$ has argued for the need for adopting the perspective of evidence-based management in the study of workplace wellbeing. Evidence-based management has its roots in the evidence-based medicine movement (Smith, 1991), which, in turn, emerged from concerns that many medical interventions were under- or mis-used (Walshe \& Rundall, 2001). Organizational researchers noted the relevance of these concerns (e.g., Pfeffer \& Sutton, 2006; Rynes et al., 2002) and called for evidence-based decision making in organizations (Rousseau \& Barends, 2011).

Although researchers have typically attributed the lack of evidence-based practice in organizations to a lack of knowledge on the part of managers (e.g., Charlier et al., 2011; Rynes et al., 2002, 2007), Kelloway $(2017,2020)$ took a different approach, suggesting that current approaches to research do not provide a basis for evidence-based practice. In short, he suggested that evidence-based management requires management-based evidence - evidence that is useful for managers to implement in organizational contexts (Kelloway, 2020).

Three suggestions for research emerged from this perspective. First, as have others, Kelloway (2020) noted the need for longitudinal research in the study of work and wellbeing. Although others have recognized the need for pre- 
dictive longitudinal studies (Ployhart \& Vandenburg, 2010) - research that examines the predictors of change over time - there is also a need for descriptive longitudinal studies of workplace wellbeing (Kelloway \& Francis, 2012). Descriptive longitudinal studies would examine how the form, direction, and timing of changes in wellbeing changes over time (e.g., Garst et al., 2000). Such descriptive studies are necessary to understand the nature of workplace wellbeing.

Intervention studies (see also Nielsen et al.'s Chapter 11 in this volume) are notoriously difficult to conduct in organizations (Karinika-Murray \& Biron, 2015) but remain the single most compelling source of knowledge about workplace wellbeing. Intervening in organizations to change a potential influence on individual wellbeing and assessing whether that intervention had the desired effect teaches us a great deal about the causes of individual wellbeing in the workplace. If we can do that intervention in the context of an experimental design that isolates the nature of the change, then we have learned even more about workplace wellbeing.

Finally, Kelloway (2020) identified the need to identify dose-response relationships as an important move forward in the study of work and wellbeing. All too often, our research leads to bromides that provide little guidance for implementation or practice. Finding that workload is a stressor that negatively affects wellbeing, for example, provides little information that would inform an organization's attempts to intervene. Most jobs have at least some periods of elevated workload and reducing workload may lead to a condition of underload which, in itself, can have deleterious consequences (e.g., Pindek et al., 2018). What is needed is evidence that supports a more precise intervention (e.g., evidence as to how much workload is "too much" in terms of wellbeing). Research methods that focus on associations or correlations between continuous measures, provide little such guidance. Techniques such as Receiver Operating Characteristic (ROC) analysis, widely used in epidemiological and medical research, may provide a means of establishing cutoffs for common organizational stressors (see for example Blanc et al., 2014).

ROC analysis requires a dichotomous outcome - classically in medical research a "diagnosis". Organizational researchers have tended to use more continuous measures of outcomes (e.g., measures of wellbeing, absenteeism etc.) and are well aware of the dangers of dichotomizing such outcomes (e.g., MacCallum et al., 2002). Although problematic in research that focuses on establishing relationships between predictors and outcomes, we suggest that such a strategy might be necessary in order to move from research to practice. 


\section{About this book}

As reflected in the contributions to this volume, both methodological and substantive challenges face researchers focused on work and wellbeing. We believe that the experts who have contributed chapters have done a remarkable job of summarizing a voluminous literature and identifying research agendas that would move the field forward.

James Campbell Quick - a noted researcher and inaugural editor of the Journal of Occupational Health Psychology - sets the scene for the volume by reviewing the historical evolution of the field (Chapter 2). He moves beyond history to identify six innovative ways to move the study of work and wellbeing forward. First, he suggests that researchers could profitably engage in multidisciplinary research that avoids reliance on the theory and methods of a single discipline. He also points to the potential benefits that could be obtained through a focus on outliers (whether individuals or organizations) and high risk situations or occupations where the costs of failure are high. Fourth, he advocates for research focused on screening and surveillance mechanisms in the workplace to improve early identification of problems and early intervention. The final two recommendations deal with the focus of research, Quick argues that there is value in taking a segmented approach, focusing on individuals who are most at risk and those who are in the top 10 percent of performers. He also recognizes a broader view that focuses on workplaces, rather than individuals, as the unit of analysis.

Christian Van Stolk continues to set the scene by examining the costs of workplace stress in Chapter 3. His particular focus is on the costs experienced by U.K. employers and employees and he presents interesting data from the Britain's Healthiest Workplaces survey. He points to the significant costs associated with stress and impaired wellbeing in the workplace and their implication for productivity and, by extension, the economic health of society.

In Part II of the book we move to a consideration of factors that influence wellbeing in the workplace. In Chapter 4, Shani Pupco and Julian Barling offer an intriguing agenda focused on leadership in organizations. They begin by reviewing the substantial literature relating leadership and employee wellbeing, but then turn the question on its head by considering how leaders' own mental health affects leadership and, thereby, employees. This leads to their call for a greater focus on leaders' wellbeing. Following calls for multi-disciplinary approaches, they then look beyond the traditional leadership or occupational health psychology literatures to identify novel research questions. They con- 
clude with a consideration of issues related to sex and both sexual and gender identities. In taking this diverse perspective, Pupco and Barling identify both novel and important questions that significantly expand the literature on leadership and wellbeing.

In Chapter 5, Ivana Vranjes, Zhanna Lyubykh and M. Sandy Herschovis consider the influence of workplace aggression on workplace wellbeing. Their particular focus is on the role of observers to workplace aggression. They begin with a broad view of what, in theory, observers can do in organizations and then consider the empirical evidence as to what observers actually do and when they do it. They conclude by considering identifying research questions dealing with intervention effectiveness, the consequences experienced by observers that intervene, and the consequences for observers that do not intervene.

In Chapter 6, Arla Day, Ryan Cook, Rachael Jones-Chick and Vanessa Myers examine the links between information and communications technology (ICT) and wellbeing. They begin by reviewing the extant literature showing the multiple ways in which ICT use can affect wellbeing. They develop a four-pronged framework, integrating the physical effects of ICT use, ICT as a conduit for demands and resources, the direct and indirect effects of ICT use and the directionality of the ICT use-wellbeing relationship. They articulate research questions emerging from each of these perspectives and, in doing so, provide a structured research agenda for future research on ICT use and its contribution to wellbeing in the workplace.

In Chapter 7, Winny Shen and Kristen M. Stockley consider the influence of work-family concerns on individual wellbeing. They offer a constructive critique of this literature - arguing that the field is at a crossroads and must move beyond the pervasive use of cross-sectional research designs to establish a relationship between work-family issues and strain. Specifically, they suggest three new directions for work-family research; questioning whether researchers truly understand the constructs underlying commonly used measures, whether interventions have been targeted toward the most effective points, and whether we should expect to, or try to, change individual work-family experiences.

In Part III of the book, we focus on interventions targeted toward improving wellbeing in the workplace. The section begins with Jennifer K. Dimoff, Whitney E.S. Vogel and Olivia Yoder's consideration of mental health in the workplace. They point to the prevalence of mental health issues in society that are reflected in the workplace and the need for organizations to intervene to 
assist employees. After highlighting organizations that have done an effective job in this area, Dimoff et al. also point to the numerous questions that remain for researchers to address.

In Chapter 9, Sheena Johnson and Elinor O'Connor consider stress management interventions. After introducing a conceptual model of stress management interventions, they identify both substantive and methodological areas in which research on stress management can be advanced. They also identify the changing nature of work as an influence on stress management interventions.

Mindfulness interventions are the focus of Maree Roche, Michelle R. Tuckey and Ute R. Hülsheger in Chapter 10. They review existing research pointing to the nature and potential benefits of mindfulness in the workplace. However, they also note the areas in which more research is needed. These include greater conceptual clarity in the nature of mindfulness, the development of a stronger evidence base through greater methodological rigor and a greater understanding of mindfulness in the context of the workplace.

Karina Nielsen, Caroline Axtell and Glorian Sorensen move beyond the focus on individual intervention to consider the nature of organizational interventions in Chapter 11. Their particular focus is participatory interventions and how the context can shape the nature and effectiveness of the intervention. They draw on the IGLOO (individual, group, leader, organizational and outer context) framework to identify the relevant contextual influences.

As mentioned at the beginning of this chapter, this volume unfolded in the midst of the worldwide Covid-19 pandemic. It quickly became apparent that issues arising from the pandemic would likely influence the nature of work and the nature of organizational research for the future. In Chapter 12, Gary $\mathrm{W}$. Ivey and his team consider the implications of the pandemic for research on work and wellbeing, identifying potential influences and research questions.

We feel fortunate to have secured the participation of these experts in creating a research agenda for research on work and wellbeing. We believe that, both individually and collectively, the contributors to this volume have posed a considerable challenge for researchers to address a myriad of issues related to work and wellbeing. We are also confident that researchers will respond to these challenges in order to create better workplaces that positively influence wellbeing. 


\section{References}

American Institute of Stress (2005). Workplace Stress. Accessed on August 27, 2015. Retrieved from http://www.stress.org/workplace-stress/

Attridge, M., Cahill, T., Granberry, S.W., \& Herlihy, P.A. (2013). The National Behavioral Consortium industry profile of external EAP vendors. Journal of Workplace Behavioral Health, 28(4), 251-324.

Baicker, K., Cutler, D., \& Song, Z. (2010). Workplace wellness programs can generate savings. Health Affairs, 29(2), 304-311.

Blanc, S., Zamorski, M., Ivey, G., Edge, H. M., \& Hill, K. (2014). How much distress is too much on deployed operations? Validation of the Kessler Psychological Distress Scale (K10) for application in military operational settings. Military Psychology, 26(2), 88-100. https://doi.org/10.1037/mil0000033

Canadian Medical Association (2013). Mental Health. Accessed on August 3, 2015. Retrieved from https://www.cma.ca/En/Pages/mental-health.aspx

Canadian Standards Association (2013). Psychological Health and Safety in the Workplace: Prevention, Promotion, and Guidance to Staged Implementation. Ottawa, Ontario, Canada: Canadian Standards Association.

Charlier, S., Brown, K., \& Rynes, S. (2011). Teaching evidence-based management inMBA programs: What evidence is there? Academy of Management Learning \& Education, 10(2), 222-236.

Corrigan, P. (2004). How stigma interferes with mental health care. American Psychologist, 59, 614.

Dimoff, J.K. and Kelloway, E.K. (2016). Resource utilization model: Organizational leaders as resource facilitators. In W.A. Gentry, C. Clerkin, P.L. Perrewé, J.R.B. Halbesleben, and C.C. Rosen (eds), Research in Occupational Stress and Wellbeing Volume 14: The Role of Leadership in Occupational Stress. London, UK: Emerald, pp. 141-160.

Dimoff, J.K., \& Kelloway, E.K. (2019). With a little help from my boss: The impact of workplace mental health training on leader behaviors and employee resource utilization. Journal of Occupational Health Psychology, 24(1), 4-19.

Dimoff, J.K., Kelloway, E.K., \& MacLellan, A.S. (2014). Health and performance: Science or Advocacy? Journal of Organizational Effectiveness: People and Performance, 1, 316-334.

Dozois, D.J. (2020). Anxiety and depression in Canada during the COVID-19 pandemic: A national survey. Canadian Psychology/Psychologie canadienne 62(1), 136-142.

Garst, H., Frese, M., \& Molenaar, P.C.M. (2000). The temporal factor of change in stressor-strain relationships: A growth curve model on a longitudinal study in East Germany. Journal of Applied Psychology, 85, 417-438.

Goetzel, R.Z., \& Ozminkowski, R.J. (2008). The health and cost benefits of work site health-promotion programs. Annual Review of Public Health, 29, 303-323.

Goetzel, R.Z., Roemer, E.C., Liss-Levinson, R.C., \& Samoly, D.K. (2008). Workplace health promotion: Policy recommendations that encourage employers to support health improvement programs for their workers. A paper commissioned by Partnership for Prevention, Emory University, available at: www.prevent.org/data/ files/initiatives/workplacehealtpromotionpolicyrecommendations.pdf

Gilbert, S.L., \& Kelloway, E.K. (2018). Leadership, recognition and well-being: A moderated mediational model. Canadian Journal of Administrative Sciences/Revue canadienne des sciences de l'administration, 35(4), 523-534. 
Grawitch, M., Gottschalk, M., and Munz, D. (2006). The path to a healthy workplace: A critical review linking healthy workplace practices, employee wellbeing, and organizational improvements. Consulting Psychology Journal: Practice and Research, $8,129-147$.

Gulseren, D.B., Thibault, T., Kelloway, E.K., Mullen, J., Teed, M., Gilbert,S., \& Dimoff, J.K. (in press). R.I.G.H.T. leadership: Scale development and validation of a psychologically healthy leadership model. Canadian Journal of Administrative Science.

Hunt, J., \& Eisenberg, D. (2010). Mental health problems and help-seeking behavior among college students. Journal of Adolescent Health, 46, 3-10.

Jones-Chick, R., \& Kelloway, E.K. (in press). The 3 pillars of mental health in the workplace: Prevention, intervention, and accommodation. In T. Wall, C. Cooper and P. Brough (eds), The Oxford Handbook of Organizational Wellbeing. Oxford, UK.

Karinika-Murray, M., \& Biron, C, eds (2015). Derailed Organizational Interventions for Stress and Wellbeing: Confessions of Failure and Solutions for Success, NewYork: Springer.

Kelloway, E.K. (2017). Mental health in the workplace: Towards evidence-based practice. Canadian Psychology, 58(1), 1-6. http://dx.doi.org/10.1037/cap0000084

Kelloway, E.K. (2020). Chasing the dream: The healthy and productive workplace. In P. Graf and D. Dozois (eds), Handbook on the State of the Art in Applied Psychology, New York: Wiley.

Kelloway, E.K., \& Day, A.L. (2005). Building healthy organizations: What we know so far. Canadian Journal of Behavioural Science, 37, 223-235. http://dx.doi.org/10 $.1037 / \mathrm{h} 0087259$

Kelloway, E.K., \& Francis, L. (2012). Longitudinal research and data analysis. In R. Sinclair, M. Wang, and L. Tetrick (eds), Research Methods in Occupational Health Psychology, New York: Routledge, pp. 374-394.

Keyes, C.L. (2002). The mental health continuum: From languishing to flourishing in life. Journal of Health and Social Behavior, 43(2), 207-222.

Kornhauser, A. (1965). Mental Health of the Industrial Worker, New York: Wiley

Linnan, L., Bowling, M., Childress, J., Lindsay, G., Blakey, C., Pronk, S., ... \& Royall, P. (2008). Results of the 2004 national worksite health promotion survey. American Journal of Public Health, 98, 1503-1509.

MacCallum, R.C., Zhang, S., Preacher, K.J., \& Rucker, D.D. (2002). On the practice of dichotomization of quantitative variables. Psychological Methods, 7(1), 19-40.

McDaid, D. (2011). Making the Long-term Economic Case for Investing in Mental Health to Contribute to Sustainability. European Union. Retrieved from https:// www.researchgate.net/publication/303024588_Making_the_long-term_economic _case_for_investing_in_mental_health_to_contribute_to_sustainability, Accessed July $21,2021$.

Mental Health Commission of Canada [MHCC], (2012). Changing Directions, Changing Lives: The Mental Health Strategy for Canada, Calgary, AB.

National Alliance on Mental Illness (2019). Mental health by the numbers. Retrieved from https://www.nami.org/learn-more/mental-health-by-the-numbers, July 21, 2021.

Pfeffer, J., \& Sutton, R. (2006). Evidence-based management. Harvard Business Review, 84(1), 63-74.

Pindek, S., Krajcevska, A., \& Spector, P.E. (2018). Cyberloafing as a coping mechanism: Dealing with workplace boredom. Computers in Human Behavior, 86, 147-152.

Ployhart, R.E., \& Vandenberg, R.K. (2010). Longitudinal research: The theory, design, and analysis of change. Journal of Management, 36, 94-120. 
Reynolds, G.S., \& Lehman, W.E. (2003). Levels of substance use and willingness to use the employee assistance program. Journal of Behavioral Health Services \& Research, 30, 238-248.

Rousseau, D., \& Barends, E. (2011). Becoming an evidence-based HR practitioner. Human Resource Management Journal, 21(3), 221-235.

Ryff, C.D. (1989). Happiness is everything, or is it? Explorations on the meaning of psychological wellbeing. Journal of Personality and Social Psychology, 57(6), 1069.

Rynes, S., Colbert, A., \& Brown, K. (2002). HR professionals' beliefs about effective human resource practices: Correspondence between research and practice. Human Resource Management, 41, 149-174.

Rynes, S., Giluk, T., \& Brown, K. (2007). The very separate worlds of academic and practitioner periodicals in human resource management: Implications for evidence-based management. Academy of Management Journal, 50(5), 987-1008.

Sauter, S.L., Murphy, L.R., and Hurrell, Jr., J.J. (1990). Prevention of work-related psychological disorders. American Psychologist, 45, 1146-1153.

Secretary of Health, Education and Welfare (1974). Work in America (A Report of a Special Task Force to the Secretary of Health, Education, and Welfare). Cambridge, MA: MIT Press.

Smith, R. (1991). Where is the wisdom...? The poverty of medical evidence. British Medical Journal, 303, 798-799.

Spector, P.E., \& Pindek, S. (2016). The future of research methods in work and occupational health psychology. Applied Psychology, 65(2), 412-431.

Taris, T., Kessler, S., \& Kelloway, E.K. (in press). Editorial: Strategies addressing the limitations of cross-sectional designs in occupational health psychology: What they are good for (and what not). Work \& Stress, 35(1), 1-5.

Walshe, K., \& Rundall, T. G. 2001. Evidence-based management: From theory to practice in health care. Milbank Quarterly, 79, 429-457.

World Health Organization (1948). Preamble to the Constitution of the World Health Organization as adopted by the International Health Conference, New York, 19-22 June 1946, and entered into force on 7 April 1948. Available at https://www.who.int/ about/who-we-are/constitution. Accessed June 3, 2021.

World Health Organization (2002). Prevention and Promotion in Mental Health. Accessed on January 20, 2020. Retrieved from https://www.who.int/mental_health/ media/en/545.pdf

World Health Organization (2004). The Summary Report on Promoting Mental Health: Concepts, Emerging Evidence, and Practice. Geneva, Switzerland: World Health Organization.

World Health Organization (2019) Mental health in the workplace: Information sheet. Available at: https://www.who.int/mental_health/in_the_workplace/en/ (accessed 24 June 2020). 